$\frac{\frac{\pi}{2}}{\frac{\delta}{0}}$

\title{
Ciudad Educadora entre la realidad y la utopía
}

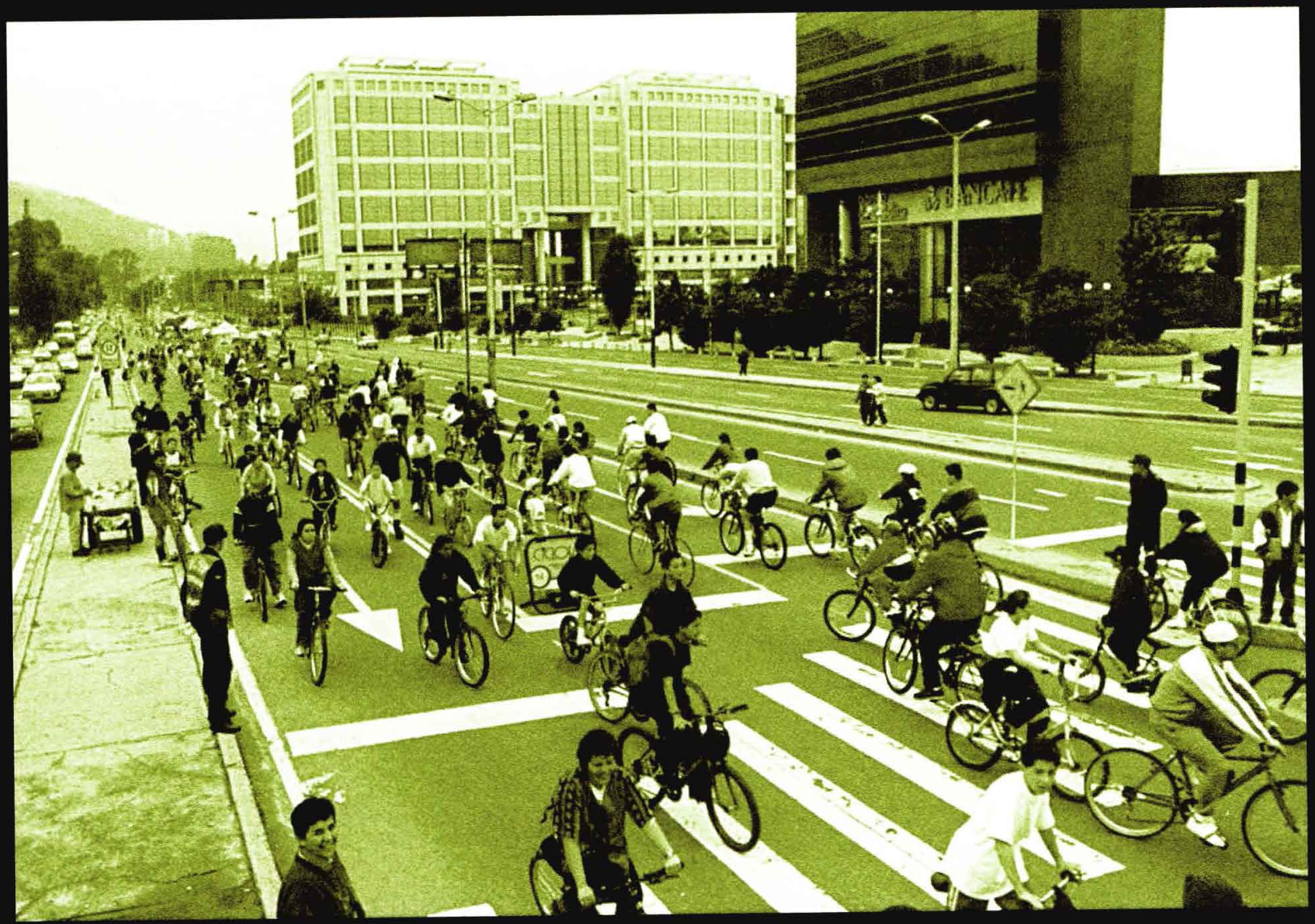




\section{Patricia Bryon}

Filósofa, con estudios de maestría en educación con énfasis en comunidad. Actualmente, se desempeña como docente de la Universidad Distrital, Facultad Tecnológica, Ciudad Bolívar, y de la Universidad Santo Tomás, Facultad de Comunicación Social. Coordina el grupo S de Ciudad Bolívar, de la Cátedra Pedagógica: Bogotá, una gran escuela.

\section{Gustavo Gaona}

Estudiante de noveno semestre de licenciatura en educación básica con énfasis en humanidades y lengua castellana, de la Universidad Distrital. Actualmente es monitor del grupo grupo S de Ciudad Bolívar, de la Cátedra Pedagógica: Bogotá, una gran escuela.

\section{Resumen}

El presente artículo hace algunas consideraciones sobre Ciudad Educadora entendida como un proyecto político, que debe tener como propósito central el mejoramiento de las condiciones de sus ciudadanos, permitiendo que lleven una vida digna. Dados los parâmetros, se centra en la realidad de la localidad de Ciudad Bolívar y el trabajo que vienen desarrollando los docentes en ésta.

\section{Palabras clave}

Ciudad Educadora, utopía, derecho a la ciudad, ciudadanía, esfera pública, pedagogía, escuela y comunidad, derechos humanos.

\section{Abstract}

This article presents some discusión about the Educating City understood as a political project that must have, as a fundamental purpose, the improvement of the conditions for its citizens promoting a dignified quality of life. It pertains especially to the local realities of Ciudad Bolivar (Bogotá, Colmbia) and the work that some teachers have been achieving.

\section{Key words} rights.

Educating City, utopia, Right to the City, citizenship, public sphere, pedagogy, school and community, human 


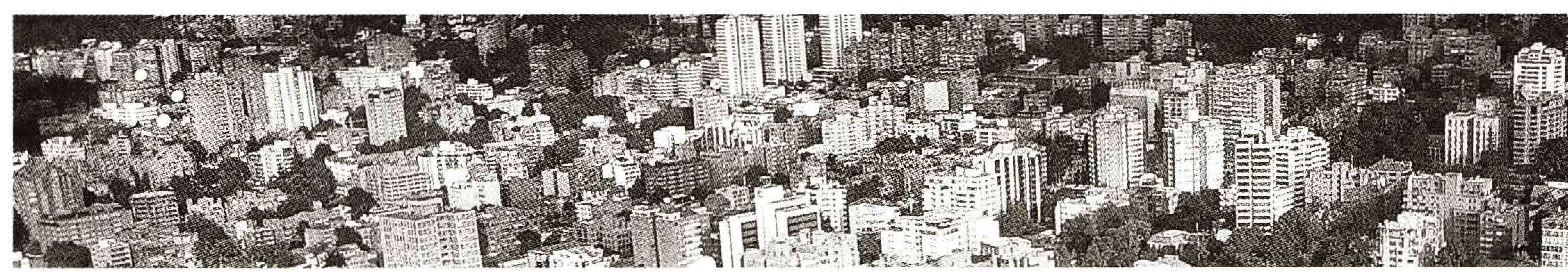

\begin{abstract}
En cuanto educadora, la ciudad también es educanda. Buena parte de su tarea educativa tiene relación directa con nuestra posición politica y, obviamente, con la manera como ejercemos el poder en la ciudad y el sueño o la utopía de que impregnamos la politica; al servicio de qué y de quién!.
\end{abstract}

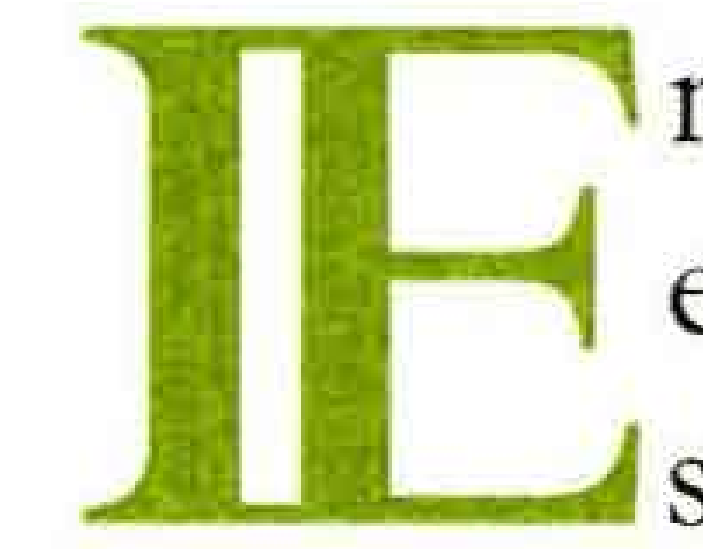
n esta afirmación de Paulo Freire, se encuentran dos elementos que han sido comunes en los planteamientos de ciudad educadora: primero, la ciudad educadora como una utopía en proceso de construcción, que, en términos de Paulo Freire, es la búsqueda de lo "inédito viable", fundamentado en una pedagogía de la esperan$z a$. El segundo elemento guarda relación directa con el anterior, ya que es el medio para su construcción; es la viabilización de unas políticas de ciudad, que determinarán el tipo de ciudadano para la 'ciudad deseo'.

Aclarar estos dos elementos, el sueño que se persigue y los medios que se construyen para conseguirlo es indispensable para entender el papel político-educativo de la ciudad. A continuación, se precisa la perspectiva que se adopta de utopía, para, desde allí, apostarle a la construcción de una ciudad educadora como proyecto político integral. En este sentido, se centrará la reflexión en el papel que tendrían la escuela y el docente como elementos fundamentales para dicha construcción. Sin embargo, se señala que el proyecto de Ciudad
Paulo Freire

Educadora no puede ser exclusiva de la escuela, sino que se requiere un esfuerzo mancomunado de otros ámbitos y actores.

El texto concluye con la presentación de la realidad de la localidad 19 y las alternativas y cuestionamientos que han elaborado los profesores en relación con ésta.

\section{Ciudad educadora: una utopía en proceso de construcción}

En la introducción redactada por Jaume Trilla Bernet para el libro La ciudad educadora, que fue el material trabajado en el Primer Congreso Internacional de Ciudades Educadoras, realizado en Barcelona, en 1990, el autor intenta caracterizar la Ciudad Educadora por medio de diez epígrafes. En el noveno se lee: "el concepto de ciudad educadora refiere a

\footnotetext{
1 Freire, Paulo, Política y educación, México, Siglo XXI, quinta edición 2001, p. 27.
} 
la vez realidades y utopías" 2 . Si bien estas palabras pueden constituir una contradicción, en realidad denuncian una tensión no evidente.

Cuando se habla de Ciudad Educadora, en realidad se hace referencia a una alternativa al caos reinante en la ciudad. En este sentido se entendería como una utopía, ya que éstas "se ubican en el vaivén de la esperanza y de la desesperación. Desesperación frente a lo que es y esperanza en lo que debe ser" 3 por lo cual vendría a constituirse en una esperanza de aquello que debe ser.

Pero al entenderla como una utopía, no se pretende considerarla como un sueño inalcanzable o como la 'ficcionalización' producto del autor. La utopía, aquí, tendrá dos objetivos simultáneos: por una parte, se constituye en una crítica a aquello a lo que es contraria. Por otra, no es producto de un delirio romántico, sino que es un discurso que pretende ser viable y busca concretarse en una praxis social.

Si bien es cierto que la utopía se puede entender como una forma de escape imaginada por alguien para evadir la realidad que le acosa, se debe advertir que dicha creación surge de la observación atenta del contexto que rodea al creador de dicha

2 Trilla Bernet, Jaume. Introducción al libro La ciudad educadora. La ville éducatrice, en: Ponencia "La ciudad educadora: municipio y educación", realizada en el marco de la Cátedra de Pedagogía: Bogotá, una gran escuela. Experiencias nacionales e internacionales sobre ciudades educadoras, Auditorio Compensar, marzo 7, 2005.

3 Blanco, Rogelio. La ciudad ausente: utopía y utopismo en el pensamiento occidental. España, Ediciones AKAL S.A., 1999, p. 13. utopía. Es este contexto que le motiva a crear ese otro mundo.

La utopía ha surgido como una necesidad crítica frente a una situación contraria para el sujeto. De allí que R. Dahrendorf afirme que "la causa final de las construcciones utópicas es siempre, con pocas excepciones, la crítica e incluso la acusación de sociedades existentes" ${ }^{4}$.

Como forma de escape, la utopía se establece entre lo imaginado y lo real. Es una crítica establecida por medio del ejemplo concreto. De allí que la utopía se considere como un elemento necesario para el hombre, ya que no sólo critica sino que proyecta posibilidades, nuevas formas de ser y estar en las que el ser humano se pueda realizar. Para Paulo Freire, la utopía es el motor de la historia humana, como lo señala a continuación

(...) no hay utopía verdadera, fuera de la tensión entre la denuncia de un presente que se hace cada vez más intolerable y el anuncio de un futuro por crear, por construir, política, estética y éticamente entre todos; mujeres y hombres. La utopía implica esa denuncia y ese anuncio, pero no permite que se agote la tensión entre ambos, en torno a la producción del futuro antes anunciado y del nuevo presente. La nueva experiencia de

4 Dahrendorf, R. Sociedad y libertad, en Blanco, Rogelio. Op. Cit. p. 92. 
sueño se instaura en la misma medida en que la historia no se inmoviliza, no muere. Por el contrario, continúa ${ }^{5}$

Desde este punto de vista, la utopía es una mirada crítica y dialéctica de las contradicciones de la realidad, y de la superación de éstas en la búsqueda de la transformación. Es abrir el camino para las nuevas posibilidades a las que se pretende llegar. Por esta razón, una utopía no es un mero sueño, sino que se constituye en un proyecto político viable.

\section{Ciudad Educadora, como proyecto político}

Hannah Arendt entiende la política como un telos: un fin práctico, de donde el bios poliikos: el hombre en términos aristotélicos, como lo resalta la autora, es acción (praxis) y discurso (lexis), "de los que surge la esfera de los asuntos humanos" 6 . La política, por tanto, hace referencia a una posición óntico-ética, e implica una interpretación y actuación frente al mundo, atravesados por discursos y prácticas. "La política no es más que una función de la sociedad, en la que acción, discurso y pensamiento son fundamentalmente su-

5 Freire, Paulo, Pedagogía de la esperanza, Madrid, Siglo XXI, segunda edición, p. 87.

6 Arendt, Hannah. La condición humana, Barcelona, Paidós Ibérica S.A., primera edición, 1993, p. 22.

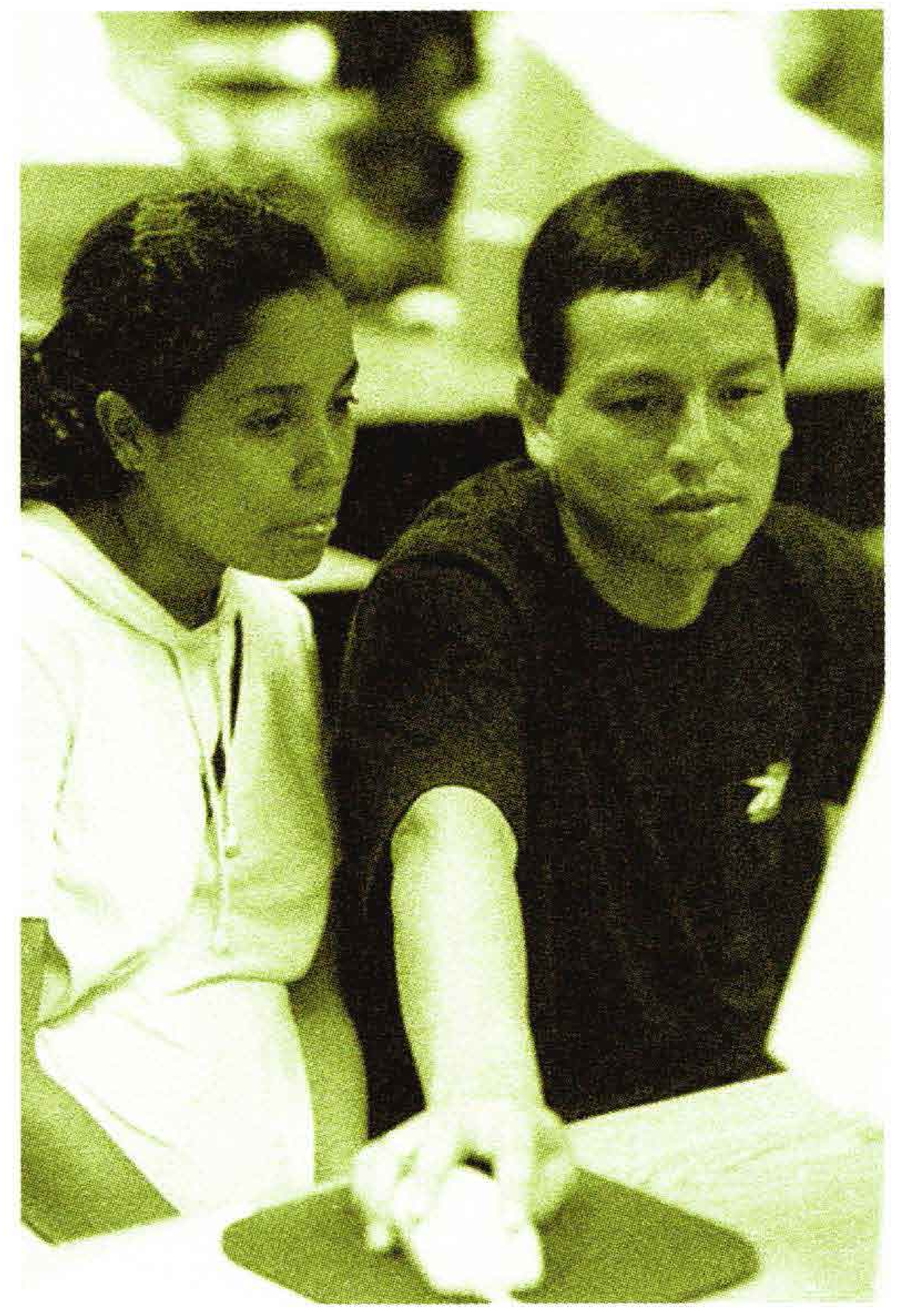

praestructuras relativas al interés social" 7. La política se construye en la esfera de lo público, en donde tiene lugar el encuentro de la pluralidad:

La realidad de la esfera pública radica en la simultánea presencia de innumerables perspectivas y aspectos en los que se presenta el mundo común, para el que no cabe inventar medida o denominador común. Pues el mundo común es el lugar de reunión de todos. Quienes están presentes, ocupan diferentes posiciones en él. Y el puesto de uno puede no coincidir más con el otro, que la posición de dos objetos. Ser

\footnotetext{
7 Ibidem. p. 45.
} 
visto y oído por otros deriva su significado del hecho de que todos ven y oyen desde una posición diferente. Este es el significado de la vida pública $(. . .)^{8}$

El espacio público desempeña un papel importante en la construcción de ciudad y de ciudadanía. Jordi Borja, en su obra Ciudad conquistada, conceptúa la ciudad como espacio público, en el que se deben conjugar elementos de redistribución social, cohesión comunitaria y autoestima colectiva. El espacio público se convierte en espacio de formación y expresión de voluntades colectivas; tanto como en espacio de representación y conflicto, como espacio de esperanza de progreso. La ciudad, en tanto territorio, puede ser el resultado de dos tendencias: una estrategia de planificación de la vida urbana y su construcción voluntaria, o un proceso de 'guetización' y fragmentación, que desemboca en un proceso de marginalidad.

En este sentido, subyace un proyecto político a una de las dos tendencias. Es decir, la ciudad se piensa como proyecto innovador, competitivo en lo global e integrador en lo local, o se convierte en espacio de contradicción y exclusión. Así, la ciudad como desafio de integración, es un territorio de conquista que concierne a todos los ciudadanos.

La ciudad es un espacio público en el que se manifiesta la democratización política y social. En consecuencia, el estatus de ciudadanía conlleva el reconoci-

\footnotetext{
8 Ibidem, p. 66.
}

miento de los ciudadanos como sujetos políticos activos, a los que se les reconoce el derecho y la posibilidad de acceder a la diversidad de las ofertas urbanas.

Por ello, la ciudad, según Borja, es el lugar de la representación y expresión de dominados y dominadores: representación del espacio público. Es aquí donde la sociedad desigual y contradictoria puede evidenciar sus conflictos.

Ante la globalización, el desafío se sitúa para los gobiernos locales y la ciudadanía. Este desafío consta de tres dimensiones: política, como derecho de los ciudadanos en la intervención de políticas públicas; social, como derecho a la promoción de politicas sociales que contrarresten la discriminación; y urbana, en un sentido simbólico donde los espacios den sentido a la vida cotidiana de la ciudad; un sentido integrador de las actividades.

La ciudad educadora, como proyecto político, significa generar las condiciones para el fortalecimiento de los procesos organizativos y participativos de los ciudadanos. Así, contribuye con la construcción del tejido social.

En este proceso lo local desempeña un papel primordial, ya que "lo político se concreta en la cotidianidad. Es alli en donde se expresan sus límites, al determinar relaciones de poder en el uso, referencia y expresión territorial" 9. Lo político como eje transversal de la

\footnotetext{
9 Rodríguez, Jahir. "Ciudad educadora: una perspectiva política desde la complejidad", en: Revista de estudios sociales, Bogotá, Universidad de los Andes y Fundación Social, № 10, octubre de 2001, p. 61.
} 
ciudad implica una nueva forma de asumir la participación, los derechos civiles, políticos y sociales, y, por tanto, la inclusión: "la posibilidad real de acceder a los derechos sociales" 10 .

La Ciudad Educadora como proyecto político se fundamenta en el reconocimiento y respeto a la pluralidad, donde los plurales comparten unos mínimos que, en términos de Adela Cortina, se concretan en el respeto a los derechos humanos, la vida como valor fundamental y la práctica de la libertad de pensamiento, movilidad y participación. Éstos, posibilitados, como bien lo señala la autora, en la potenciación de las condiciones para el ejercicio de una vida digna, son denominados por ella como los derechos sociales, económicos y culturales. Apostarle a un proyecto de ciudad educadora, en palabras de Jahir Rodríguez, significa una forma de asumir creativamente la ciudad y la ciudadanía, con potenciación de las responsabilidades sociales e individuales y de la gestión ciudadana. Así fue expresado en el Segundo Encuentro de Regiones, realizado en 1998, en la localidad de Ciudad Bolivar. "El derecho a la ciudad no es sólo al techo. También corresponde a las condiciones de vida. Es decir, al acceso a todos los servicios públicos, en buenas condiciones, a bajo costo. Y, de igual manera, al trabajo bien remunerado. Poder vivir fruto de nuestra realización personal, sintiéndonos útiles para la sociedad" ${ }^{11}$.

\footnotetext{
10 Ibidem, p. 62.

11 Corporación Taliber, Grupo de Danzas Colegio ICES-ISNEM. Potosí-La Isla, Historia de una lucha, Bogotá Difundir Ltda., 1998, p. 35.
}

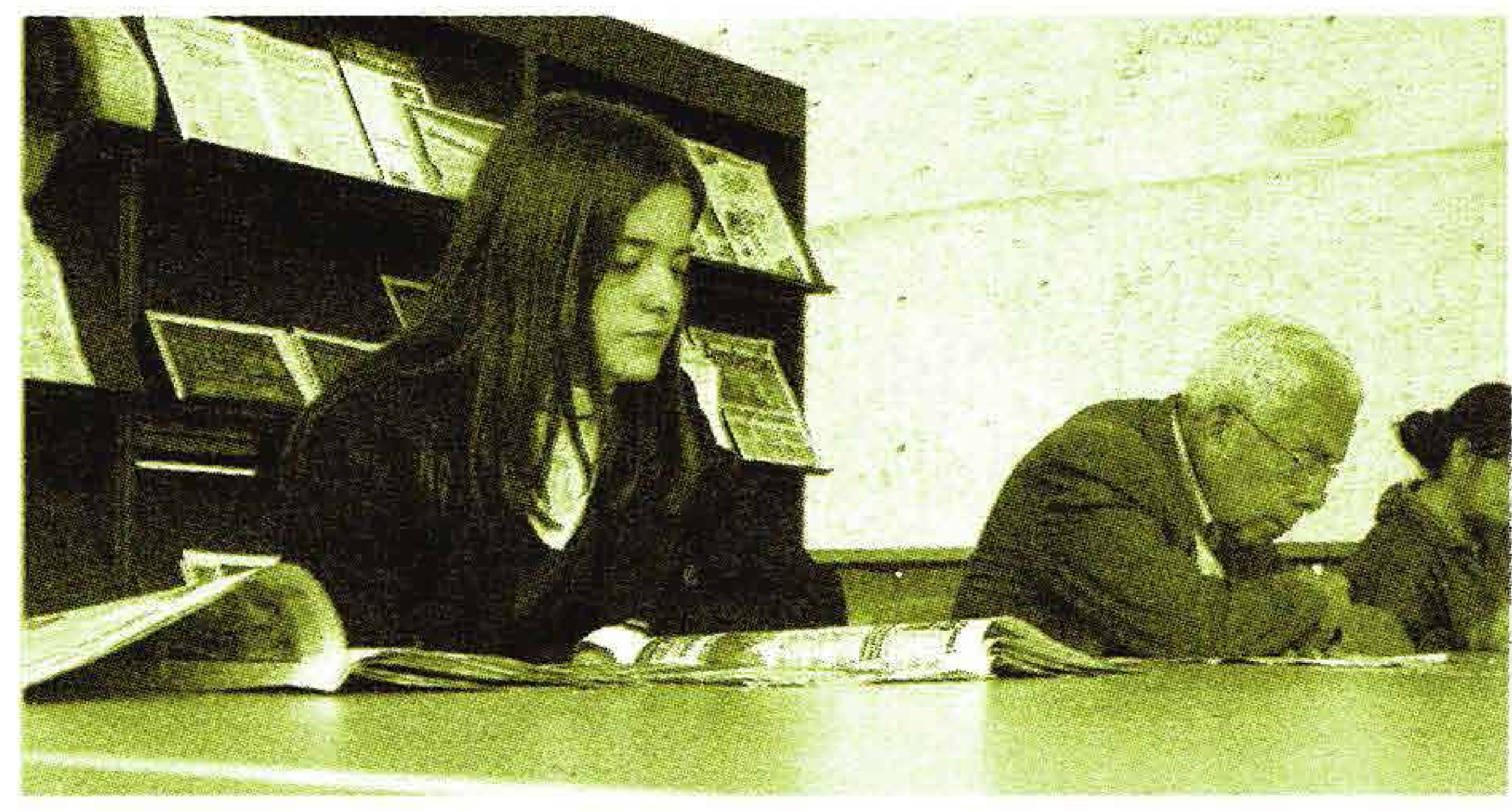

La ciudadanía, en términos de Gadotti, es "conciencia de los derechos y deberes, y ejercicio de plena democracia: derechos civiles, como seguridad y movilidad; derechos sociales, como trabajo, salario justo, salud, educación, vivienda, etc.; derechos políticos, como libertad de expresión, libertad para votar, libertad de participación en partidos políticos y sindicatos, etc. No hay ciudadanía sin democracia" ${ }^{12}$.

De conformidad con todo lo anterior, se concluye que la Ciudad Educadora es una apuesta política que sueña con una ciudad incluyente, fundamentada en el principio de la dignidad y en el respeto a la vida; una ciudad más humanizada. Desde esta perspectiva, se asume como mapa de navegación el espíritu de la Carta mundial del derecho a la ciudad, emanada en el Foro Social de las Américas llevado a cabo en Quito, en 2004. Esto, porque corresponde a la realidad que como

\footnotetext{
12 Gadotti, Moacir, "La escuela en la ciudad que educa", conferencia dictada en el marco de la Cátedra de Pedagogía: Bogotá, una gran escuela, experiencias de ciudad educadora, nacionales e internacionales, 2005.
} 
latinoamericanos vivimos y sentimos, ya que se fundamenta en el derecho a la ciudad, entendido como

el usufructo equitativo de las ciudades dentro de los principios de la sustentabilidad y la justicia social. Se entiende como un derecho colectivo de los habitantes de las ciudades, en especial de los grupos empobrecidos, vulnerables y desfavorecidos, que les confiere la legitimidad de acción y organización, basado en sus usos y costumbres, con el objetivo de alcanzar el pleno ejercicio del derecho a un patrón de vida adecuado ${ }^{13}$

En este orden de ideas, la escuela desempeña un papel importante en la formación de ciudadanía, al establecer una relación 'dialógica' con la ciudad y originar una escuela ciudadana, como lo indica Moacir Gadotti. Esta escuela es, por esencia, participativa, e implica la apropiación de la población en la gestión y la planeación de la ciudad.

\section{El papel de la escuela en la construcción de Ciudad Educadora}

La palabra pedagogía viene del griego paidos (niño) y agein (conducir) que, traducidos, quieren decir "conducir al niño". Si bien se podría decir que pedagogía es educación, habría algunas objeciones a entender estas dos palabras como equivalentes, pues las estaríamos sesgando, ya que ninguna es reducible a la otra sino que cada una cuenta con características determinadas que las diferencian. A continuación,

13 Preámbulo, Carta mundial del derecho a la ciudad, Foro Social de las Américas, Quito, julio de 2004. 
$c$ i u d a d

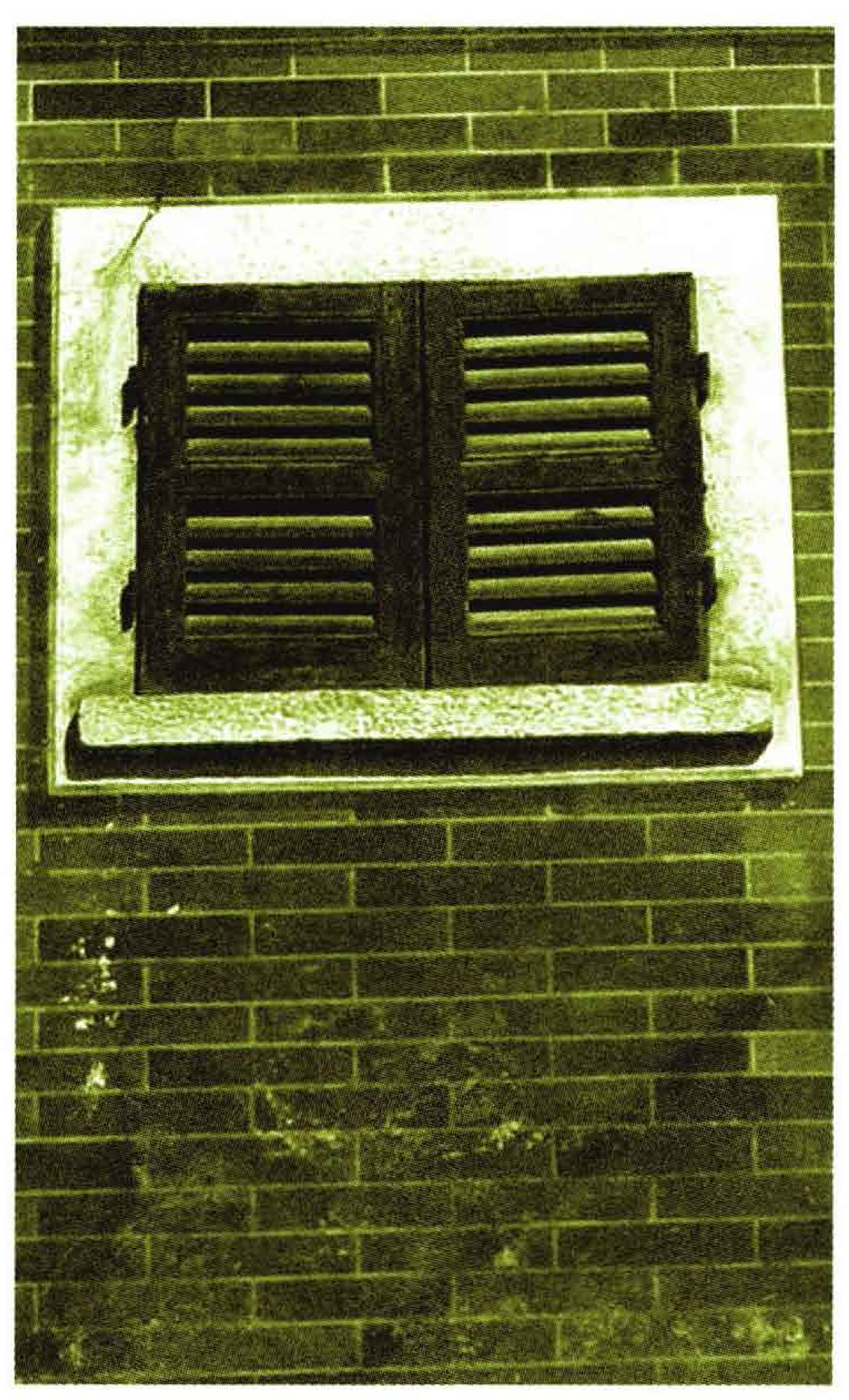

se presentará una distinción entre las dos categorías para, después, establecer el papel de la escuela en la construcción de la Ciudad Educadora.

La educación es, de acuerdo con la acepción más generalizada, un fenómeno cultural caracterizado por "la transmisión de la cultura del grupo de una generación a otra" 14 , que transfiere los elementos necesarios para que dicho grupo social sobreviva y se mantenga.

La educación, entonces, vendría siendo la forma de llevar a los sujetos a una adaptación a su medio social. Esto implica un dominio de códigos, saberes, formas de comportamiento, ritos, etc.,

\footnotetext{
${ }^{14}$ Abbagnano, N., Visalberghi, A. Historia de la pedagogía, México, Fondo de Cultura Económica, 1964, p. 16.
}

que le ayudarán a desenvolverse en su ámbito cultural, interactuando socialmente con los demás individuos.

Vista así, la educación deberá entenderse como un proceso continuo que ocurre en cualquier tiempo y espacio de la sociedad. Es decir, la educación es mucho más amplia que el sistema educativo formal. Como lo señala Jaume Trilla, hay otras educaciones (diferentes a la formal e informal) que, junto con la formal, configuran la realidad educativa de una sociedad.

En cambio, la pedagogía es "el conjunto de saberes que versan sobre la educación, elaborados con el doble propósito de elucidar los mecanismos de su producción, y orientarla y optimizarla hacia la consecución de determinados objetivos y finalidades" 15 . Dicho de otra forma, la pedagogía es aquella que reflexiona sobre el hecho educativo; sobre los procesos de enseñanza-aprendizaje, que son propios de la constitución de determinado ciudadano o sujeto.

Luego, la educación como objeto de estudio de la pedagogía es "mucho más amplia que ella. La pedagogía se ha centrado en la educación escolar y ha llegado a impactar la educación no formal, pero no ha logrado llegar al plano de la educación infor$\mathrm{mal}^{16}$. Si se entiende que la pedagogía es la reflexión

\footnotetext{
15 Trilla Bernet, Jaume. Otras educaciones. Animación sociocultural, formación de adultos y ciudad educativa, Barcelona, Anthropos, 1993, p. 18.

${ }^{16}$ Esta reflexión se encuentra ampliada en el texto de Jaume Trilla Bernet antes citado.
} 
y sistematización del hecho educativo, lo anterior señala que hay una parte de la educación que se le escapa a ésta

La pedagogía es una escritura, un discurso que versa y que intenta realizarse, transformándose en aparato sobre ųn aspecto de lo real: la educación. De la pedagogía como escritura -e incluso como aparato- podemos admitir su carácter sistémico. De la educación, sin embargo, habrá que reconocer su continua y provisionalmente renovada indomabilidad; su permanente y sutil dosis de informalidad ${ }^{17}$

Si bien ha sido sistémica, la pedagogía también ha sido proyectiva, en comparación con la educación. Como lo señala Alejandro Álvarez en la conferencia dictada en el marco de la Cátedra de pedagogía: Bogotá, una gran escuela, 2005, los planteamientos de los grandes pedagogos proponían una reforma de la escuela. Las corrientes pedagógicas siempre han optado por poner resistencia a las ataduras que se imponen a la educación desde el Estado; plantean posibilidades y potenciales cambios.

"De alli que detrás de toda utopía haya, cuando menos, un modelo pedagógico implícito o explícito, hasta el punto que algunas utopías son decididamente pedagógicas, y otras se pueden enmarcar en un subgénero pedagógico" 18 .

17 Trilla Bernet, Jaume. Op. Cit., p. 21.

${ }^{18}$ Blanco, Rogelio. Op. Cit., p. 102.
Este es un medio para concretar la utopía, una alternativa para volverla viable, ya que es ahí donde debe plantearse la formación de ese nuevo ciudadano que se exige para lograr el cambio del sistema social propuesto por la utopía.

Y es que, más allá, todo proyecto pedagógico tiene un componente utópico. "Desde Tomas Moro a Babeuf, desde H. Saint-Simon a J. Proudhon, desde J.J. Rousseau a Pestalozzi, desde la Educación Nueva a C. Freinet o Freire o Ilich, reforma educativa y reforma social se presentan paralelas, inevitablemente unidas la una a la otra" ${ }^{19}$. La pedagogía siempre se ha sembrado sobre la esperanza de un cambio en la sociedad en que se vive.

La educación y la pedagogía, de acuerdo con lo anterior, deben ser entendidas como un acto político que configura la construcción del sujeto social, en el cual el maestro desempeña un papel central, ya que es el responsable de reflexionar sobre el proceso de enseñanza-aprendizaje y de transformarlo de acuerdo con las consideraciones surgidas desde esa reflexión. En pocas palabras, es el encargado de dinamizar el mismo acto pedagógico, el cual es siempre un acto político.

Entendido así, en el acto de enseñar no circulan discursos neutros porque las "escuelas son lugares que representan formas de conocimiento, usos lingüísticos, relaciones sociales y valores que implican selecciones y exclu-

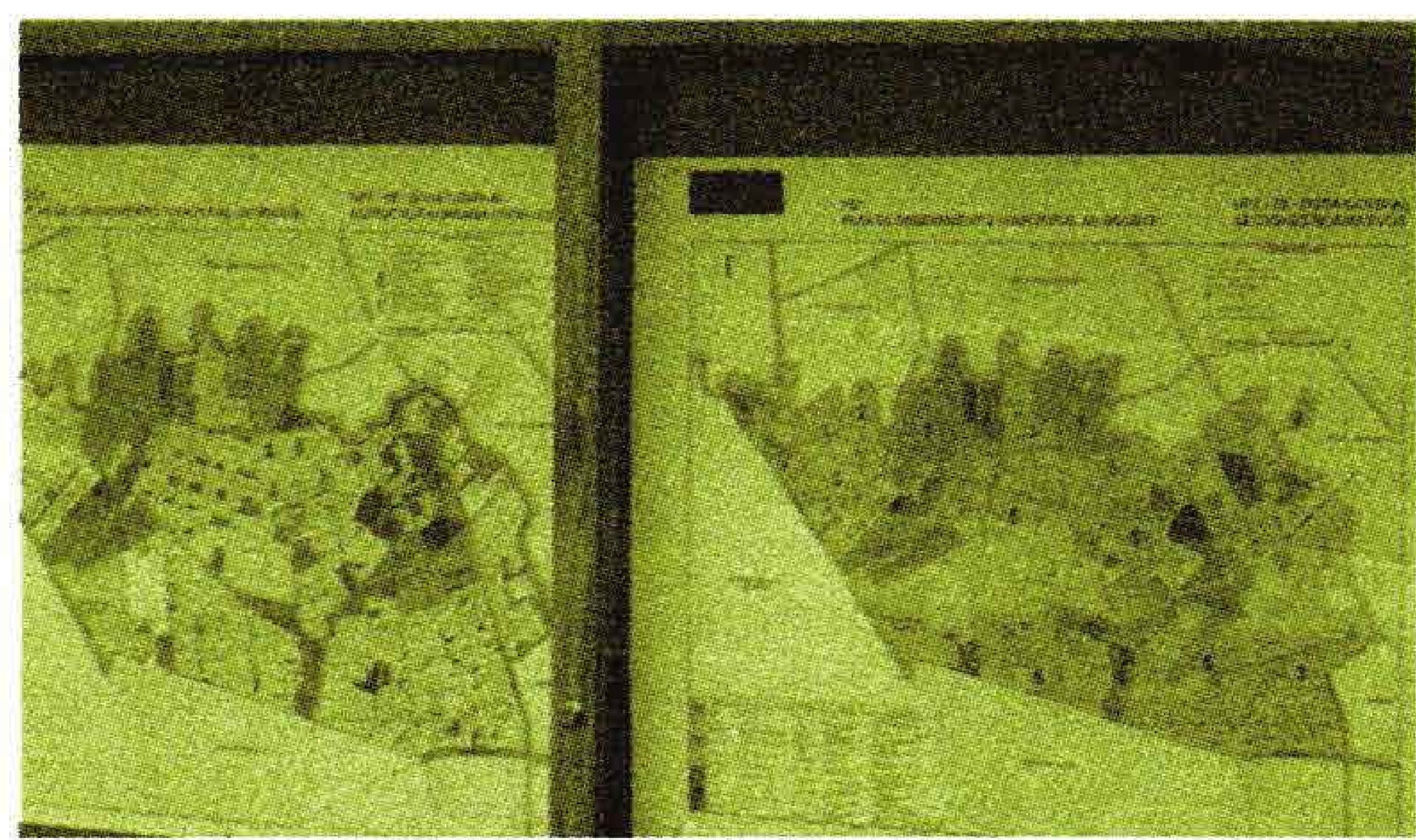

19 Ibidem, p. 104. 
siones particulares a partir de la cultura general"20. Esto significa que la escuela excluye unos tipos de conocimiento que son propios de algunos grupos sociales, pugnando por una acomodación indolora a un tipo de conocimiento que le permitirá perpetuarse. En este sentido, la objetividad del maestro también quedaría en cuestionamiento, ya que las escuelas no son lugares neutrales " $y$, por consiguiente, tampoco los profesores pueden adoptar una postura neutral" ${ }^{21}$. En el fondo, el acto de enseñar está determinado por alguna de dos posiciones políticas: se legitima un discurso, o se transforma. Esto exige asumir una posición ética-politica y transformadora, desde la asunción del maestro, desde sus sueños y utopías de un mundo posible. Dicha idea ha sido plasmada por Freire, así

Lo que me mueve a ser ético, por sobre todo, es saber que la educación es, por su propia naturaleza, directiva y política. Yo debo respetar a los educandos, sin jamás negarles mi sueño o mi utopía. Defender una tesis, una posición, una preferencia, con seriedad y con rigor, pero también con pasión, estimulando y respetando al mismo tiempo el derecho al discurso contrario, es la mejor forma de enseñar, por un lado, el derecho a tener el deber

\footnotetext{
20 Giroux, Henry. Los profesores como intelectuales, España, Paidós Ibérica, 1997, p. 291.

21 Ibidem, p. 177.
}

de 'pelear' por nuestras ideas y por nuestros sueños -y no sólo aprender las sintaxis del verbo haber-; y, por otro lado, enseñar el respeto mutuo.

Respetar a los educandos, sin embargo, no significa mentirles sobre mis sueños, decirles con palabras o gestos o prácticas que el espacio de la escuela es un lugar sagrado, donde solamente se estudia, y que estudiar no tiene nada que ver con lo que ocurre en el mundo afuera; ocultarles mis opciones, como si fuera 'pecado' preferir, optar, romper, decidir, soñar. Respetarlos significa, por un lado, darles testimonio de mi elección, defendiéndola; por el otro, mostrarles otras posibilidades de opción, mientras les enseño, no importa qué ${ }^{22}$

El maestro, entonces, debe revisar su propio capital cultural y evaluar como éste se encuentra mediado por unas condiciones sociales, politi-

\footnotetext{
${ }^{22}$ Freire, Paulo. La educación en la ciudad. México, Siglo XXI S.A., 1999, p. 19.
}

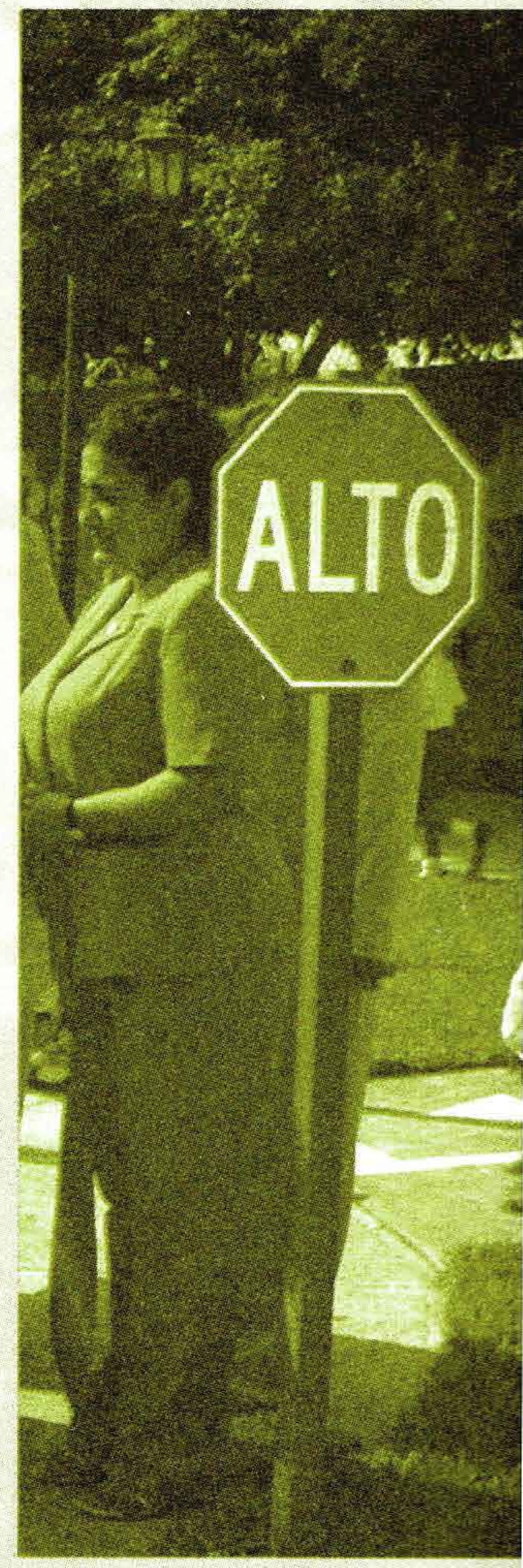


cas y culturales. Este ejercicio le permitirá observar cómo esa formación propia de su profesión ha determinado un discurso en el que no se ven reflejados los estudiantes a los que enseña. Desde allí, el docente debesempezar a replantearse el ejercicio de la enseñanza; reflexionado sobre sí mismo y sobre el acto que implica enseñar, lo cual significa asumirse "como ser social e histórico, como ser pensante, comunicante, transformador, creador, realizador de sueños, capaz de sentir rabia, porque es capaz de amar; asumirse como sujeto, porque es capaz de reconocerse como objeto"23.

En este sentido, el docente empezará a entender que el conocimiento no se debe centrar en la transmisión, sino que debe incentivar la criticidad de la realidad social, el aqui y el ahora, el contexto inmediato de los 'discentes'. Afirma Freire que "la localidad de los educandos es el punto de partida para el conocimiento que van creando del mundo. 'Su mundo', en última instancia, es el primero e inevitable rostro del mundo mismo" 24.

Por estas razones, tanto la escuela como el docente desempeñan un papel preponderante en la construcción política-pedagógica de la ciudad educadora, porque, asumiéndose en su papel transformador, crean una comunión entre la es-

${ }^{23}$ Freire, Paulo. Pedagogía de la autonomía. Saberes necesarios para la práctica educativa, Buenos Aires, Siglo XXI, S.A., 2002, p. 42.

${ }^{24}$ Freire, Paulo. Pedagogía de la esperanza. México, Siglo XXI, Segunda edición, p. 87. cuela y la comunidad conformada por sujetos hacedores de su propia historia. En este sentido, Freire llama la atención respecto a que "la calidad de la escuela deberá ser medida no sólo por la cantidad de contenidos transmitidos y asimilados, sino igualmente por la solidaridad de clase que haya construido, por la posibilidad de que todos los usuarios de la escuela -incluidos padres y comunidad-tuvieron que utilizarla como un espacio para la elaboración de su cultura" ${ }^{25}$.

Teniendo este compromiso social, se debe entender que se reconoce la escuela como uno de los escenarios para construir ese proyecto político; pero no es el único. La Ciudad Educadora debe ser entendida como un entramado complejo, en el que entran en juego las cosmovisiones de los diferentes actores, las instituciones, las dinámicas sociales, las realidades históricas y las nuevas formas de habitarla.

Visto de esta manera, la escuela es un posible escenario en el que, por tanto, una viabilización de Ciudad Educadora implicaría poner en diálogo activo a las instituciones escolares con los aspectos antes nombrados.

Hasta aquí vemos lo que implica pensar en una Ciudad Educadora. Pero esta realización hace necesarias unas condiciones para llevarse a cabo. A continuación, mostraremos las tensiones que se ha-

${ }^{25}$ Freire, Paulo. Educación en la ciudad, México, Siglo XXI, S.A., 1999, p. 19. 
cen evidentes cuando se trata de adoptar un discurso cuando aún están por construirse las condiciones para su ejecución.

\section{Entre la utopía y la realidad local: la apuesta de los docentes de Ciudad Bolívar}

Hasta el momento, la reflexión sobre ciudad educadora se ha asumido como la utopía de buscar que ésta sea mucho más humana. Razón por la cual se debe considerar como incluyente permitir la participación activa de sus habitantes para definir los rumbos que ésta tomará, y permitir una vida digna a sus ciudadanos. También se señaló que una utopía debe plantearse como viable, para lograr transformar la realidad que crítica. En este apartado, se quiere mostrar esas condiciones que vive la Localidad 19, para detallar los temas que van centrando la construcción de una utopía local desde los docentes. Se encuentran visiones distintas, centradas en el cambio social; diferentes, pero todas con el propósito claro de lograrlo, de proyectar un futuro mejor para los habitantes de esta localidad.

Las condiciones de vida de los pobladores de Ciudad Bolívar no son, por mucho, las ideales, y, en la mayoría de los casos, ni siquiera son las mínimas. La localidad tiene un índice de pobreza y miseria alto; el 2,6\% de la población registra necesidades insatisfechas. Esta cifra revela un estimado de la problemática social, económica, ambiental y de salubridad de la comunidad. Según datos de planeación de 2002, la población de la localidad es de 658.477 habitantes. De ellos, la mayoría pertenece a los estratos uno y dos: "el estrato uno al $59.7 \%$ y el dos al $35.7 \%$, correspondiendo un porcentaje de sólo $4.6 \%$ al estrato tres" 26 .

La historia de Ciudad Bolivar es un ejemplo de las contradicciones generadas por la no planeación de la ciudad, que, junto con el fenómeno del desplazamiento - producto del conflicto social y armado-, el oportunismo de

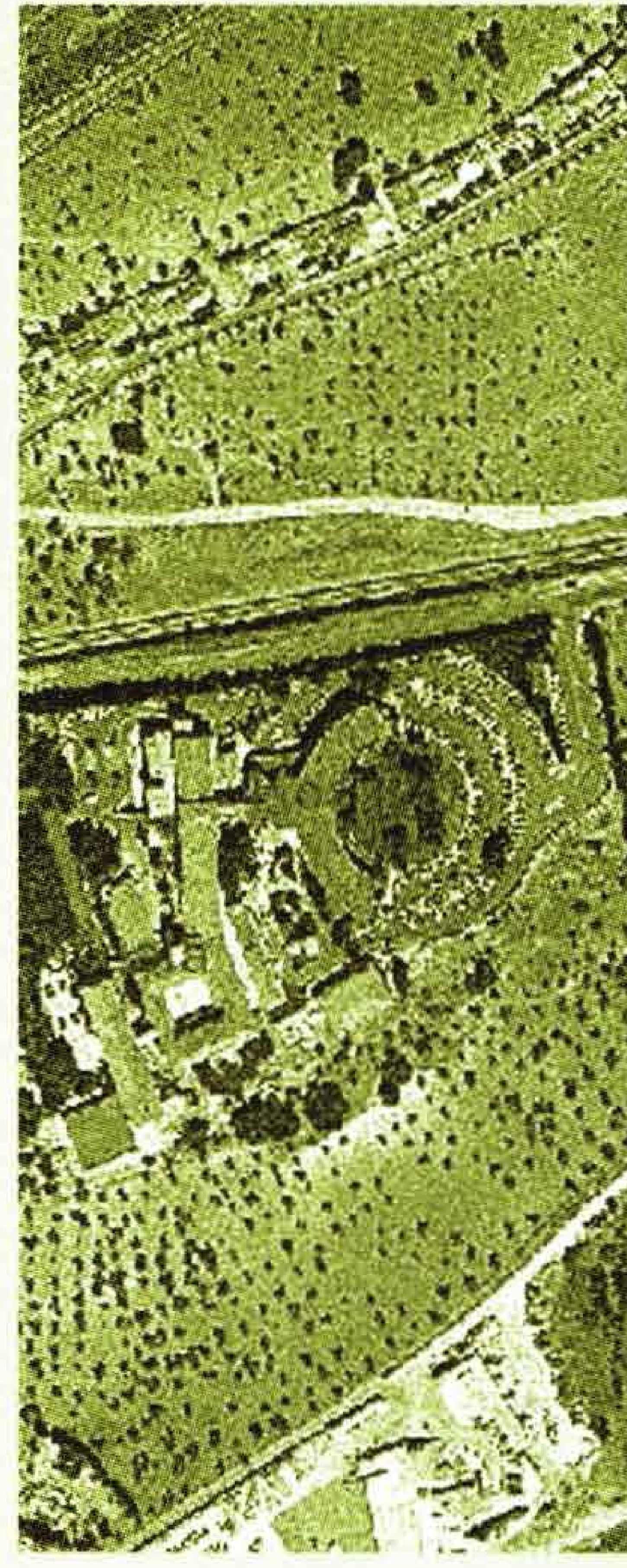
los urbanizadores piratas, el olvido estatal y el manejo de los medios, han contribuido a estigmatizarla como zona de riesgo y de peligro.

Ciudad Bolívar, denominada por Arturo Alape como hoguera de ilusiones, lleva también en su memoria la lucha por la impunidad de la violación selectiva y sistemática de los Derechos Humanos, y las reinvidicaciones justas y esperanzadoras de los movimientos sociales y comunitarios que luchan permanentemente por una vida digna, en lo posible. Esta es una Localidad donde las dinámicas organizativas han logrado, además de la autocons-

${ }^{26}$ Departamento Administrativo de Planeación Distrital. DAPD. Subdirección de Desarrollo Social. Física social y demográfica, 2002, p. 53. 


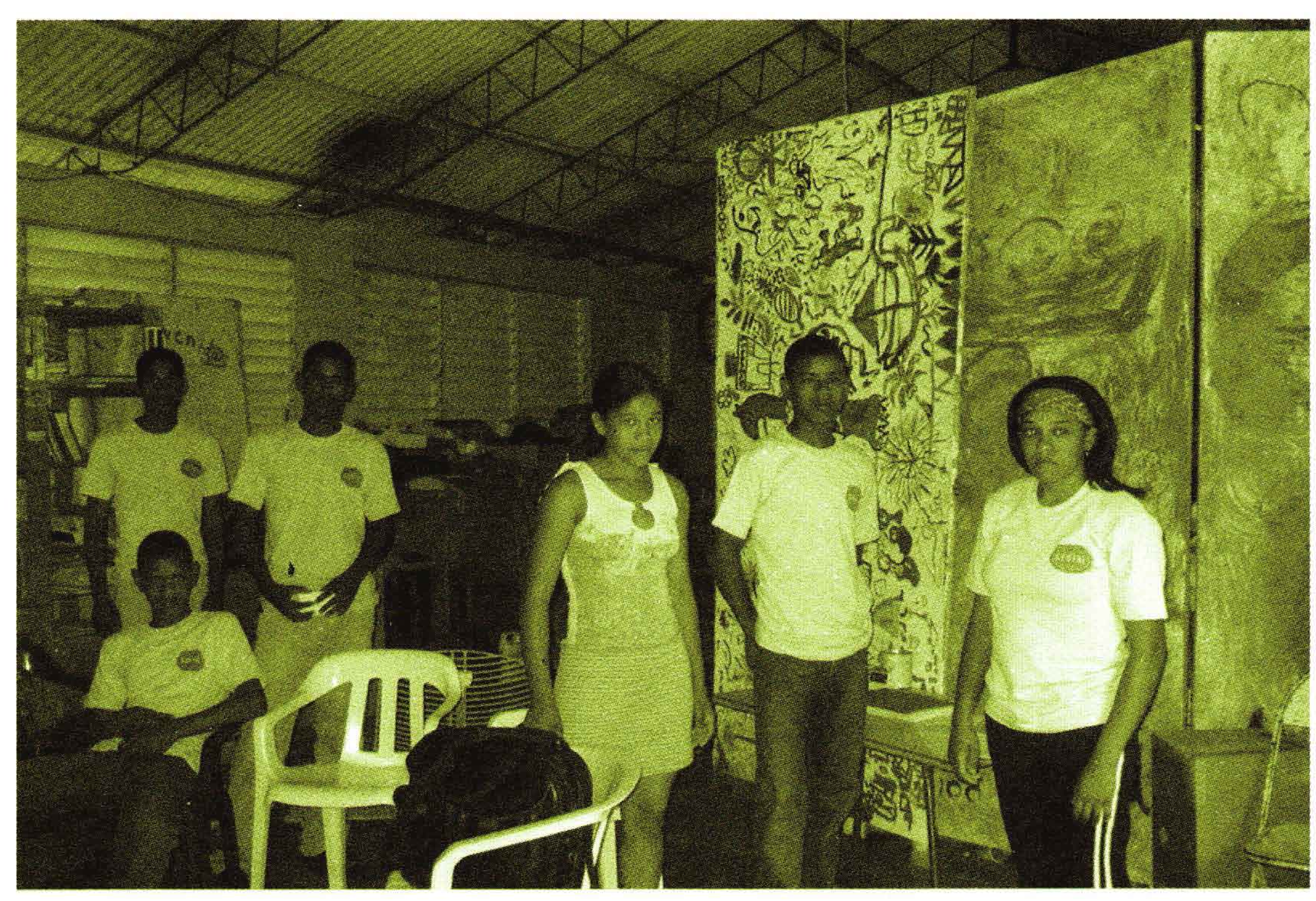

trucción de sus viviendas, la obtención de servicios públicos a través de más de una movilización para ser escuchados por los funcionarios del Estado. Su incidencia ha llegado hasta la realización de un paro cívico.

En este orden de ideas, la historia de muchas de las escuelas de Ciudad Bolívar demuestra su relación estrecha con la comunidad. Ésta, además de luchar por la vivienda y los servicios públicos, ha pensado en la construcción de un lugar donde sus hijos se puedan educar. Sus iniciativas han antecedido, en más de una ocasión, al Estado; como lo relata uno de los docentes del Colegio ICES-ISNEM: "cuando a Evaristo le propusieron hacer un colegio, se animó y empezó la gestión de los terrenos, gracias a la Fundación Social que fió unas casetas... y fiadas se quedaron. En ese tiempo, trabajábamos de manera voluntaria, trabajamos honoris causa por 16 años, hasta que el colegio entró en concesión con la Secretaría" 27.

El docente y líder comunitario Evaristo Bernate Castellanos ${ }^{28}$ impulsó un proceso de organización y gestión en la comunidad; en 1984, fundó el Colegio desde los postulados pedagógicos de Makarenko, Freinet y Freire. Estos planteamientos se ven plasmados en el PEI de la Institución, que lleva como título Escuela-Comunidad. En él, ha sido central la apropiación del Colegio por parte de la comunidad; ésta se ha convertido en un ám-

${ }^{27}$ Entrevista realizada el 29 de septiembre de 2005 por Karla Salguero, pasante de Comunicación Social de la Universidad Santo Tomás, quien realiza el proyecto Relatos sobre ciudad educadora de los docentes asistentes a la Cátedra de Pedagogía: Bogotá, una gran escuela.

${ }^{28}$ Líder asesinado en 1991. 


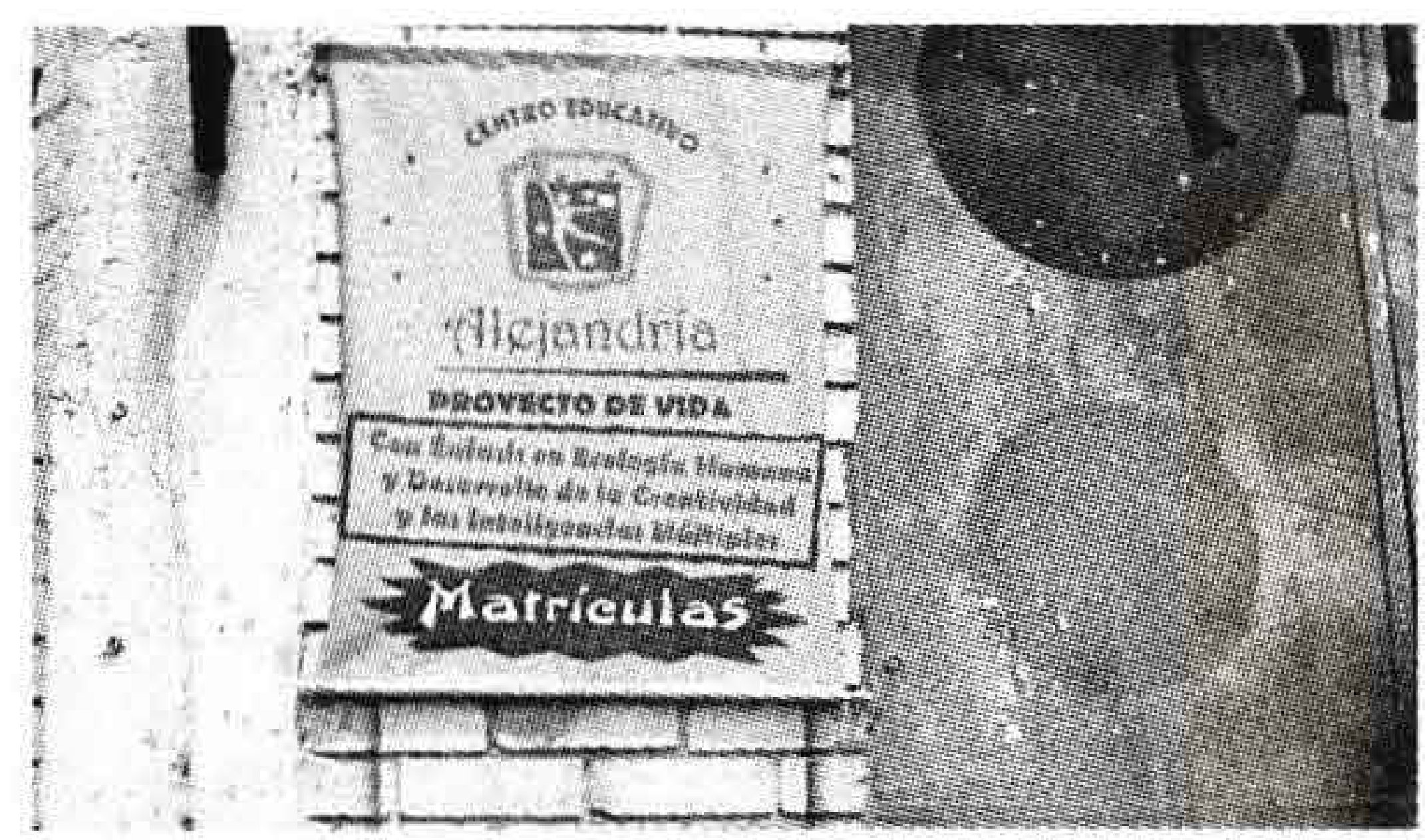

bito vital para ellos. "Cuando hablamos de EscuelaComunidad, no podemos hacer una separación del colegio, como una urna respecto a la comunidad. El proyecto tiene razón de ser en tanto espacio abierto a toda la comunidad, desarrollando la parte pedagógica, simultáneamente en el espacio físico del colegio y en el espacio abierto de la comunidad" 29.

Con esta visión, el Colegio ha desarrollado esta propuesta de manera integral junto con la Junta de Acción Comunal, la Parroquia y los coordinadores de cuadra. Esto, con el fin de sentar una plataforma participativa de solución a los problemas, por parte de la misma comunidad, a través de la viabilización de proyectos como bioseguridad alimentaria, madres comunitarias, Derechos Humanos y vivienda, entre otros.

La preocupación por el respeto a la vida y, por tanto, a los Derechos Humanos -factor que implica la construcción de relaciones convivenciales, fundamentadas en el ejercicio de la democracia- ha marcado las reflexiones de algunos maestros asistentes, para quienes la escuela debe desempeñan un papel importante en los procesos de formación, promoción y análisis de este tema, así como de la normatividad establecida al respecto.

Esta preocupación constituye un elemento de relevancia en la actual coyuntura local, que corresponde a uno de los momentos en que más se ha vul-

${ }^{29}$ Corporación Taliber, Grupo de Danzas Colegio ICES-ISNEM. Op. Cit., p. 68. nerado el respecto a la vida de los jóvenes. En 2005, más de 150 jóvenes fueron asesinados por grupos de 'limpieza social'.

En respuesta a ello, los jóvenes de Ciudad Bolivar realizaron una movilización en septiembre de 2005. Con la consigna Para que la vida siga siendo joven, expresaron su compromiso con la defensa de la vida, alegría, solidaridad, justicia y dignidad, y exigieron al Estado la protección del derecho fundamental a la vida.

Un interrogante central al proyecto de Bogotá, Ciudad Educadora ha sido la inclusión y la puesta en marcha de políticas que propenden por el derecho a la vida. En términos de Alicia Cabezudo, "es un imperativo politico y social de primera magnitud".

Otra entrada a la Ciudad Educadora, que se ha considerado importante en la reflexión local, es la relación ciudad-contexto-escuela, a partir de las expediciones pedagógicas a la ciudad. Las reflexiones de los equipos docentes parten de una premisa: la ciudad es un ámbito importante de apropiación de conocimiento. La ciudad asumida como de uso pedagógico permite significarla y 're-significarla', hacer de ella un espacio intencional educativo que hace posible el conocimiento vivencial.

El aula se hace extensiva a la ciudad. En este orden de ideas, los docentes han reflexionado sobre la incidencia del programa Escuela-Ciudad-Escuela en las posibilidades pedagógicas que la implementación del programa permite, y en las limitaciones generales. 
El abordaje de la cultura es otra de las entradas con la que los docentes han iniciado su reflexión sobre la ciudad educadora. Ésta refleja las tensiones entre las dinámicas de lo global y lo local, y el papel del maestro en el reconocimiento y apropiación de las estéticas culturales que contribuyen a la identidad, así como las estrategias y alternativas de resistencia a la cultura hegemónica difundida por los espacios mediáticos.

La cultura es reconocida, en los discursos de los maestros, como un dispositivo de apropiación de la ciudad por parte de los jóvenes, quienes desde sus singularidades y sensibilidades la 're-semantizan', a través de la construcción de las territorialidades de su cuerpo y de sus lenguajes.

Finalmente, el trabajo de la Cátedra de Pedagogía: Bogotá, una gran escuela ha permitido que se vuelvan a poner en escena las diferentes lecturas y escrituras de ciudad de los docentes, quienes habían sido silenciados por las anteriores administraciones. Este aspecto ha sido relevante, ya que permitió constituir grupos de reflexión al interior de las instituciones escolares y proyectar una nueva dinámica en las aulas. Igualmente, se constituyó un espacio de diálogo a nivel interinstitucional, permitiendo así la retroalimentación pedagógica de las experiencias locales.

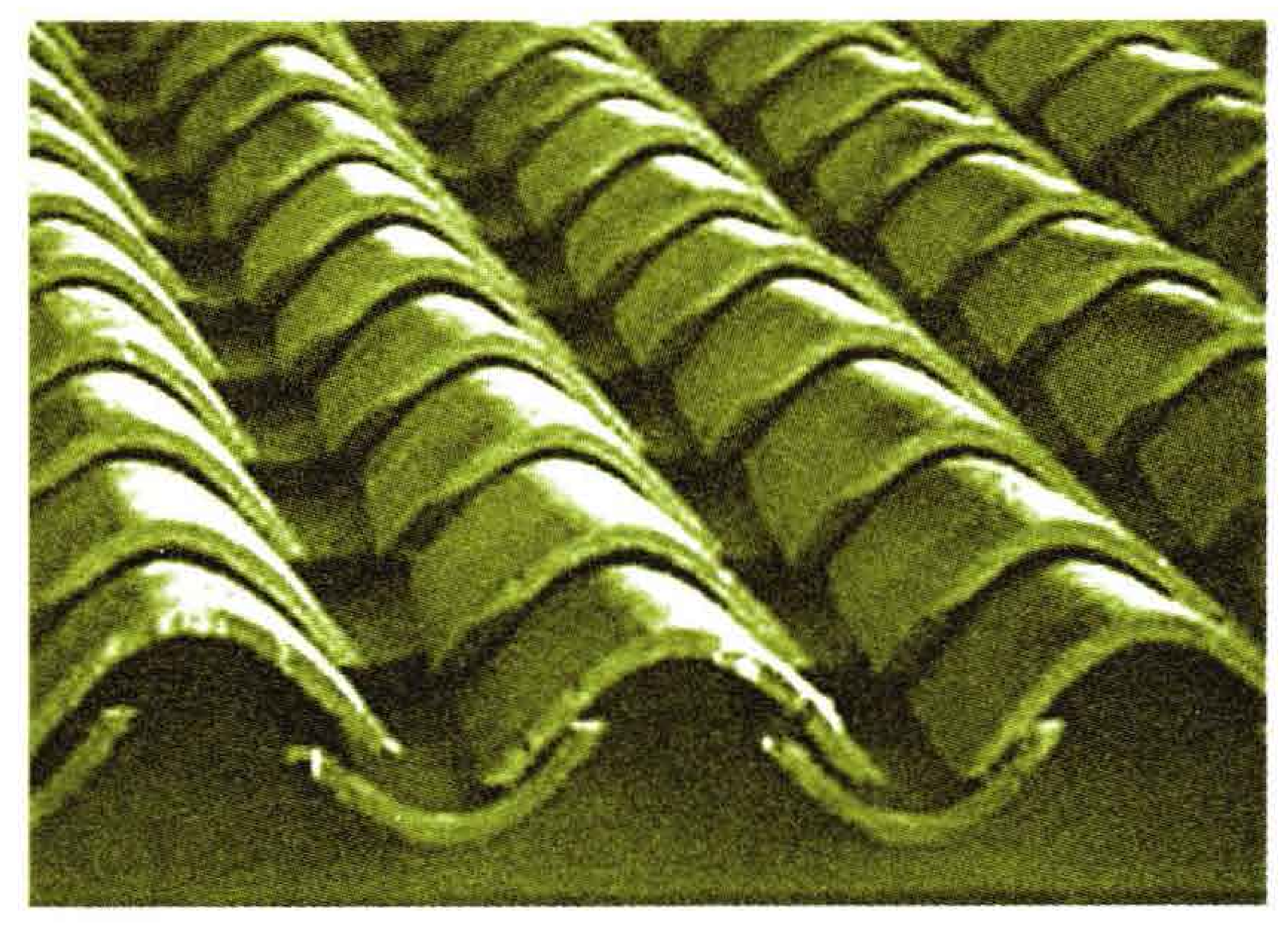




\section{Bibliografía}

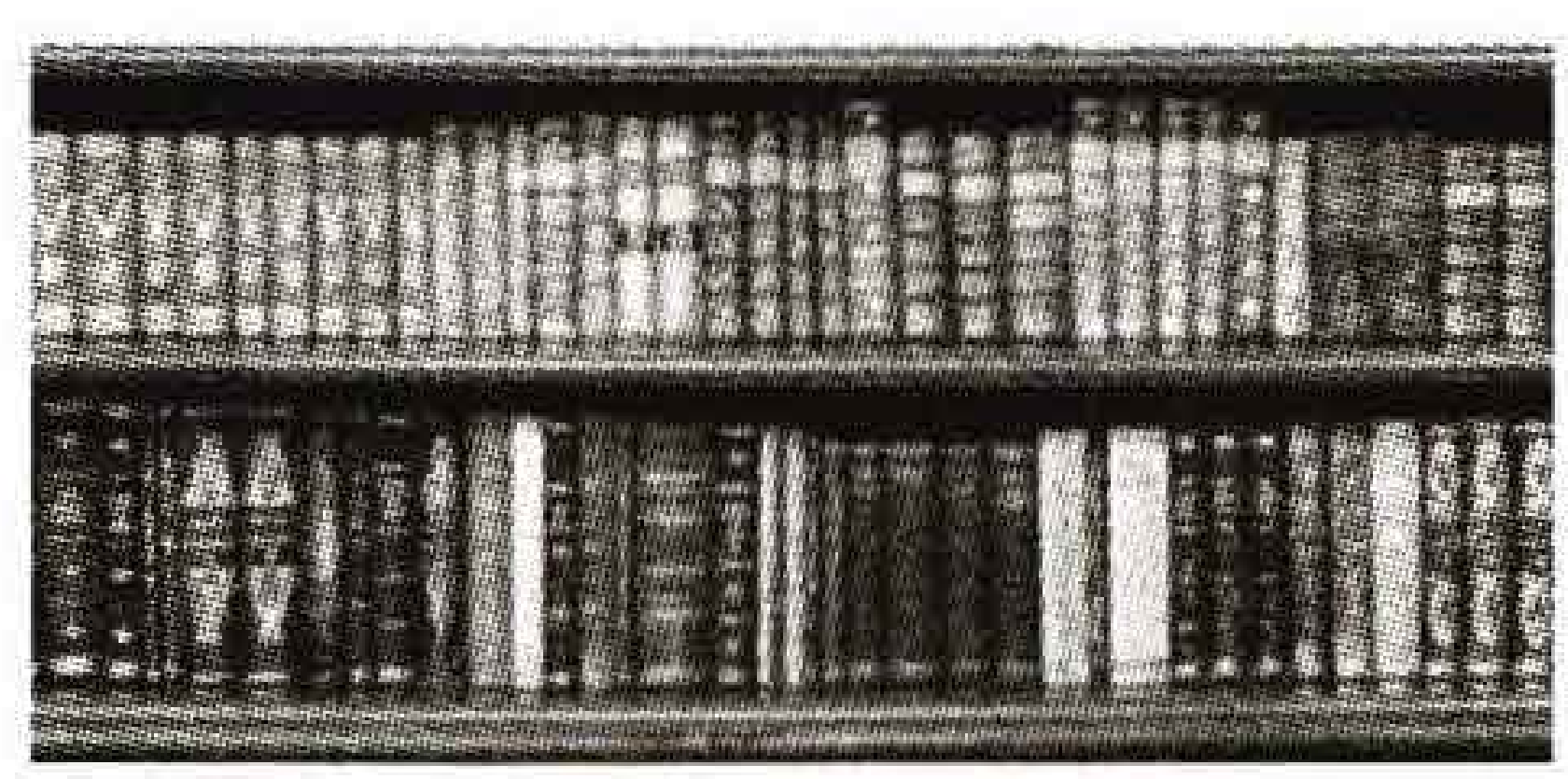

Abbagnano, N., Visalberghi, A. Historia de la pedagogía, México, Fondo de Cultura Económica, 1964, p. 668.

Álvarez, Alejandro. "Los límites de la escuela". Conferencia dictada en el marco de la Cátedra de Pedagogía: Bogotá, una gran escuela. Experiencias de ciudad educadora, nacionales e internacionales, 2005.

Arendt, Hannah. La condición humana, Barcelona, Paidós Ibérica S.A., primera edición, 1993, p. 366.

Blanco, Rogelio. La ciudad ausente: utopía y utopismo en el pensamiento occidental, España, AKAL S.A, 1999, p. 245.

Borja, Jordi. La ciudad conquistada, Madrid, Alianza S.A., 2003, p. 381.

Cabezudo, Alicia. "Ciudad Educadora: un espacio para el aprendizaje para la construcción de nuevas ciudadanías". Conferencia dictada en el marco de la Cátedra de Pedagogía: Bogotá, una gran escuela. Experiencias de ciudad educadora, nacionales e internacionales, 2005.

Carta mundial del derecho a la ciudad. Foro Social de las Américas. Quito, julio de 2004. Foro Mundial Urbano, Barcelona, octubre de 2004.
Corporación Taliber, Grupo de Danzas, Colegio ICES-ISNEM. Potosí-La Isla. Historia de una lucha, Difundir Ltda., Bogotá, 1998, p. 92.

Departamento Administrativo de Planeación Distrital, DAPD, Subdirección de Desarrollo Social. Física social y demográfica, 2002, p. 53

Freire, Paulo. Pedagogía de la autonomía. Saberes necesarios para la práctica educativa. Argentina, Siglo XXI, 2002, p. 139.

Paulo. Pedagogía de la esperanza, México, Siglo XXI, S.A. de C.V., segunda edición, p. 99.

Paulo. La educación de la ciudad. México, Siglo XXI, S.A. de C.V., 1999, p. 169.

Paulo. Política y educación. Siglo XXI Editores, México, S.A. DE C.V., 2001, p. 132.

Gadotti, Moacir. "La escuela en la ciudad que educa". Conferencia dictada en el marco de la Cátedra de Pedagogía: Bogotá, una gran escuela. Experiencias de ciudad educadora, nacionales e internacionales, 2005.

Giroux, Henry. Los profesores como intelectuales, Madrid, Paidós Ibérica, 1997, p. 290. 
Jaramillo, Jaime. Historia de la pedagogía, como historia de la cultura, Bogotá, Fondo Nacional Universitario, 1990, p. 135.

Rodríguez Rodríguez, Jahir. "Ciudad educadora: una perspectiva política desde la complejidad". En

- Revista de estudios sociales, número 10, Bogotá, Universidad de los Andes y Fundación Social, octubre de 2001, p. 47-62.

Torres Carrillo, A., Torres Azocar, J. C., "Subjetividad y sujetos sociales, en la obra de Hugo Zemelman”, Revista Folios, número 12, Bogotá, págs. 12-22.

Trilla Bernet, Jaume. Introducción al libro La Ciudad educadora, La ville éducatrice. En La ciudad educadora: municipio y educación, Conferencia dictada en el marco de la Cátedra de Pedagogía: Bogotá, una gran escuela. Experiencias de ciudad educadora, nacionales e internacionales, 2005.

Jaume. Otras educaciones. Animación sociocultural, formación de adultos y ciudad educativa, Barcelona, Anthropos, 1993, p. 220. 